\title{
Combined application of Embelin and tumor necrosis factor- related apoptosis-inducing ligand inhibits proliferation and invasion in osteosarcoma cells via caspase-induced apoptosis
}

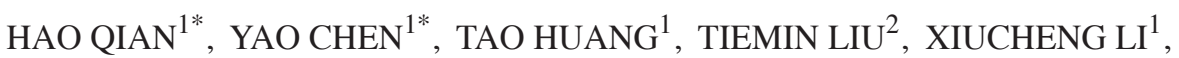 \\ GUANGJIAN JIANG ${ }^{2}$, WEI ZHANG ${ }^{1}$, SHUO CHENG ${ }^{1}$ and PENGCHENG LI ${ }^{1}$
}

${ }^{1}$ Department of Orthopedics, The First Affiliated Hospital of China Medical University, Shenyang, Liaoning 110001, P.R. China; ${ }^{2}$ Beth Israel Deaconess Medical Center, Harvard Medical School, Boston, MA 02215, USA

Received March 5, 2017; Accepted January 26, 2018

DOI: $10.3892 / \mathrm{ol} .2018 .8209$

\begin{abstract}
Embelin, as an inhibitor of the X-linked inhibitor of apoptosis protein (XIAP), may induce apoptosis in various types of cancer cells. The present study aimed to determine the effect of Embelin on the tumor necrosis factor-related apoptosis-inducing ligand (TRAIL)-induced apoptosis of osteosarcoma cells. Embelin and TRAIL were applied to U2OS and MG63 cells, respectively or in combination. MTT was initially used to detect the difference in survival rates between the group receiving combined application of $100 \mathrm{ng} / \mathrm{ml}$ TRAIL and $20 \mu \mathrm{mol} / 1$ Embelin and the individual application groups. Light microscopic quantification was used to detect the morphology of the osteosarcoma cells in each group. Determination of cell apoptosis was subsequently performed using flow cytometry. The invasive ability of the cells was detected by a Transwell assay, prior to relative protein expression being determined by western blot analysis. Based on all the test data, it was revealed that the survival rates and the invasive ability were significantly lower following the combined application of $100 \mathrm{ng} / \mathrm{ml}$ TRAIL and $20 \mu \mathrm{mol} / \mathrm{l}$ Embelin than following the individual application of either $(\mathrm{P}<0.01)$. Additionally, upregulating expression of caspases, as well as death receptor 5, and downregulating expression of XIAP and matrix metalloproteinase 9 (MMP-9), had more significant effects in the combined group compared with the individual group and the control group. All these results suggested that Embelin may enhance TRAIL-induced apoptosis and inhibit the invasion of human osteosarcoma cells.
\end{abstract}

Correspondence to: Dr Tao Huang, Department of Orthopedics, The First Affiliated Hospital of China Medical University, 155 Nanjing North Street, Shenyang, Liaoning 110001, P.R. China E-mail: huangtao@mail.cmu.edu.cn

*Contributed equally

Key words: osteosarcoma, Embelin, TRAIL, apoptosis, invasion

\section{Introduction}

Osteosarcoma is the most common type of bone cancer and it usually occurs in children and adolescents. It was also revealed that metastasis to the lung occurs quickly in patients with osteosarcoma (1). Although neoadjuvant chemotherapy in osteosarcoma has greatly enhanced the survival rate, numerous patients suffer from toxic side effects due to long-term application of chemotherapeutic drugs. Tumor necrosis factor (TNF)-related apoptosis-inducing ligand (TRAIL) is a biological agent that was identified in recent years, has a selective killing effect on tumor cells without causing damage to normal cells and has been considered to be a promising novel biological treatment in the near future $(2,3)$. A large number of human tumor cells are sensitive to the apoptosis induced by TRAIL; however, osteosarcoma cells are not sensitive to TRAIL. Recent studies have suggested that X-linked inhibitor of apoptosis (XIAP) was frequently overexpressed in cancer cells and served an important role in the resistance to TRAIL in certain tumor cells (4-6). Embelin, identified from the fruit of the Embelia ribes BURM (Myrsinaceae), was originally discovered by screening a library of natural products derived from Oriental traditional medicine (7-9). Recently, scholars used Embelin as a small-molecule inhibitor of XIAP to induce the apoptosis of tumor cells and to restore the sensitivity of certain tumor cells to TRAIL (10). However, the therapeutic effect of Embelin on TRAIL-induced apoptosis in osteosarcoma cells has not been investigated. The present study examined whether Embelin may enhance the susceptibility of human osteosarcoma cells to TRAIL and investigated the associated mechanism.

\section{Materials and methods}

Reagents. The osteosarcoma MG-63 (code no: TCHu 124) and U2OS (code no: TCHu 88) cell lines were purchased from the Cell Research Center of the Chinese Academy of Sciences (Shanghai, China). RPMI-1640 medium, Dulbecco's modified Eagle's high glucose medium (DMEM) and trypsin were purchased from Gibco; Thermo Fisher Scientific, Inc. (Waltham, MA, USA). Embelin was obtained from Abcam 
(Cambridge, UK). Pan-caspase inhibitor z-VAD-fmk and caspase-8 inhibitor z-IETD-fmk were purchased from Abcam (Cambridge, UK). Rabbit antibodies against caspases 3 and 8, death receptor (DR) 5, XIAP and MMP-9 were purchased from Abcam.

Cell culture and research methods. The U2OS cells were cultured in RPMI-1640 medium with $10 \%$ fetal bovine serum (FBS) and the MG63 cells were cultured in DMEM with $10 \%$ FBS. The two cell lines were cultured in an incubator in a humidified $5 \% \mathrm{CO}_{2}$ atmosphere. The cells entering the logarithmic growth phase were selected. In the pre-experiment, U2OS cells $(0.8 \times 105 / \mathrm{ml})$ and MG63 cells $(1 \times 105 / \mathrm{ml})$ were inoculated in 96-well plates with culture medium (Gibco; Thermo Fisher Scientific, Inc.) containing TRAIL with concentrations of 1, 10 and $100 \mathrm{ng} / \mathrm{ml}$ or containing Embelin with concentrations of 5,10 and $20 \mu 1 / 1$ or experimental control without drug. Following culture for 12, 24 and $48 \mathrm{~h}$, $20 \mu 1$ MTT was added and incubated at $37^{\circ} \mathrm{C}$ for $4 \mathrm{~h}$, prior to being dissolved in $150 \mu \mathrm{l}$ dimethyl sulfoxide. The absorbance was subsequently measured at a wavelength of $570 \mathrm{~nm}$. According to the pre-experiment on the concentration of TRAIL and Embelin using an MTT assay, concentrations of 1,10 and $100 \mathrm{ng} / \mathrm{ml}$ were selected for the TRAIL group, concentrations of 5,10 and $20 \mu \mathrm{l} / \mathrm{l}$ for the Embelin group, and $100 \mathrm{ng} / \mathrm{ml}$ TRAIL combined with $20 \mu \mathrm{l} /$ Embelin for the combined group. A concentration of $100 \mathrm{ng} / \mathrm{ml}$ TRAIL or $20 \mu \mathrm{mol} / 1$ Embelin did not reach the half maximal inhibitory concentration at 12,24 and $48 \mathrm{~h}$, according to the pre-experiment. The study was performed using the following time intervals: 12,24 and $48 \mathrm{~h}$.

MTT assay. U2OS cells $\left(0.8 \times 10^{5} / \mathrm{ml}\right)$ and MG63 cells $\left(1 \times 10^{5} / \mathrm{ml}\right)$ were inoculated in $96-$-well plates, and were added to the culture medium (Gibco; Thermo Fisher Scientific, Inc., Waltham, MA, USA) containing reagents of different concentrations of $100 \mu \mathrm{l}$ drug or experimental control without drug. Following culture for 12, 24 and 48 h, $20 \mu 1$ MTT was added and incubated at $37^{\circ} \mathrm{C}$ for $4 \mathrm{~h}$, prior to being dissolved in $150 \mu 1$ dimethyl sulfoxide. The absorbance was subsequently measured at a wavelength of $570 \mathrm{~nm}$. The survival rate of tumor cells $(\%)=$ experimental group A value/control group A value $\mathrm{x} 100$ (11).

Detection of the morphology of apoptotic cells. The apoptotic cells were directly observed under an inverted phase contrast microscope at the magnification of $x 400$. A cover slide was placed in the 6-well plate, and following apoptosis, cells were fixed using $99.5 \%$ absolute ethyl-alcohol at $37^{\circ} \mathrm{C}$ for $10 \mathrm{~min}$ and stained with $0.5 \mathrm{ml}$ Hoechst 33258 staining solution at $37^{\circ} \mathrm{C}$ for $5 \mathrm{~min}$. Images were subsequently captured using a fluorescence microscope at the magnification of $\mathrm{x} 400$ on the object slide covered by the cover slide and a drop of anti-fading solution from Hoechst Staining kit (Beyotime Institute of Biotechnology, Shanghai, China) was added.

Determination of cell apoptosis by flow cytometry. Following culture for 12, 24 or $48 \mathrm{~h}$, apoptosis was detected using the Annexin V-fluorescein isothiocyanate (FITC) Apoptosis
Detection kit (BD Biosciences, Franklin Lakes, NJ, USA). Cells in 6 -well plates $\left(5 \times 10^{5} /\right.$ well) were detached by trypsinization and washed three times in phosphate-buffered saline, centrifuged at $4^{\circ} \mathrm{C}$ at $1,000 \mathrm{x}$ g for $5 \mathrm{~min}$ and resuspended in $195 \mu \mathrm{l}$ Annexin V-FITC binding buffer (BD Biosciences). Annexin V-FITC $(5 \mu \mathrm{l})$ was added and mixed. Following this, the U2OS and MG63 cells were stained by Annexin V-FITC in binding buffer in the dark for $10 \mathrm{~min}$ at room temperature. The cells were subsequently centrifuged at $4^{\circ} \mathrm{C}$ at $1,000 \mathrm{x} \mathrm{g}$ for $5 \mathrm{~min}$ and were resuspended in $190 \mu \mathrm{l}$ Annexin V-FITC binding buffer. Finally, $10 \mu \mathrm{l}$ propidium iodide (PI) staining solution was added and mixed at $4{ }^{\circ} \mathrm{C}$ for $15 \mathrm{~min}$. The U2OS and MG63 cells were maintained on ice in the dark and immediately subjected to flow cytometric analysis (12). The data were analyzed using the Cell Quest software (version 7.5.3; BD Biosciences, San Jose, CA, USA).

Determination of the invasion ability. The invasive ability of U2OS and MG63 cells was calculated by the number of cells that passed through a polycarbonate membrane ( $8 \mu \mathrm{mol} / 1$ pore). The chamber was washed with serum-free medium (Gibco; Thermo Fisher Scientific, Inc.), and then $20 \mu \mathrm{l}$ Matrigel (dilution, 1:8; BD Biosciences) was added to evenly cover the surface of the polycarbonate membrane. Pre-processed DMEM $(200 \mu \mathrm{l})$ containing $2 \times 10^{5}$ cells with $10 \%$ FBS was placed into the upper Transwell chamber while $600 \mu 1$ DMEM with $10 \%$ FBS was placed into the lower chamber. The Transwell invasion system was added to the cell incubator for $24 \mathrm{~h}$. The upper chamber was removed and the cells were stained with $1 \%$ crystal violet for $15 \mathrm{~min}$ at room temperature (13). Invading cells that attached to the surface of the membrane were observed under an inverted phase contrast microscope at a magnification of $\mathrm{x} 400$.

Western blot analysis. Since MG-63 cells exhibit certain characteristics of osteoblasts and U2OS cells are more malignant and stable than MG-63 cells, U2-OS cells were selected for western blot analysis (14). A total Protein Extraction kit (Beyotime Institute of Biotechnology, Haimen, China) was used to extract the total protein from U2OS cells, according to the manufacturer's protocol. Protein concentration was then determined using a bicinchoninic acid protein assay kit (Beyotime Institute of Biotechnology), according to the manufacturer's protocol. Protein ( $40 \mu \mathrm{g} / \mathrm{lane})$ was separated by $10 \%$ SDS-PAGE using an SDS-PAGE Gel kit (Beyotime Institute of Biotechnology), according to the manufacturer's protocol, prior to being transferred onto $0.2-\mu \mathrm{m}$ pore polyvinylidene fluoride membranes (Beyotime Institute of Biotechnology). The membrane was blocked with 5\% skimmed milk in TBST at room temperature for $2 \mathrm{~h}$, prior to being incubated with antibodies against the following: rabbit anti-caspase-3 (dilution, 1:5,000; cat. no. ab32351), rabbit anti-caspase-8 (dilution, 1:5,000; cat. no. ab25901), rabbit anti-DR-5 (dilution, 1:1,000; cat. no. ab199357), rabbit anti-XIAP (dilution, 1:1,000; cat. no. ab21278; all Abcam) and rabbit anti-MMP-9 (dilution, 1:1,000; cat. no. 10375-2-AP; ProteinTech Group, Inc., Chicago, IL, USA) in TBST containing $1 \%$ bovine serum albumin overnight at $4^{\circ} \mathrm{C}$. A rabbit anti- $\beta$-actin monoclonal antibody (dilution, 1:5,000; cat. no. ab8227; Abcam) was used as a control for caspase- 3 and caspase- 8 while a rabbit anti-GAPDH 

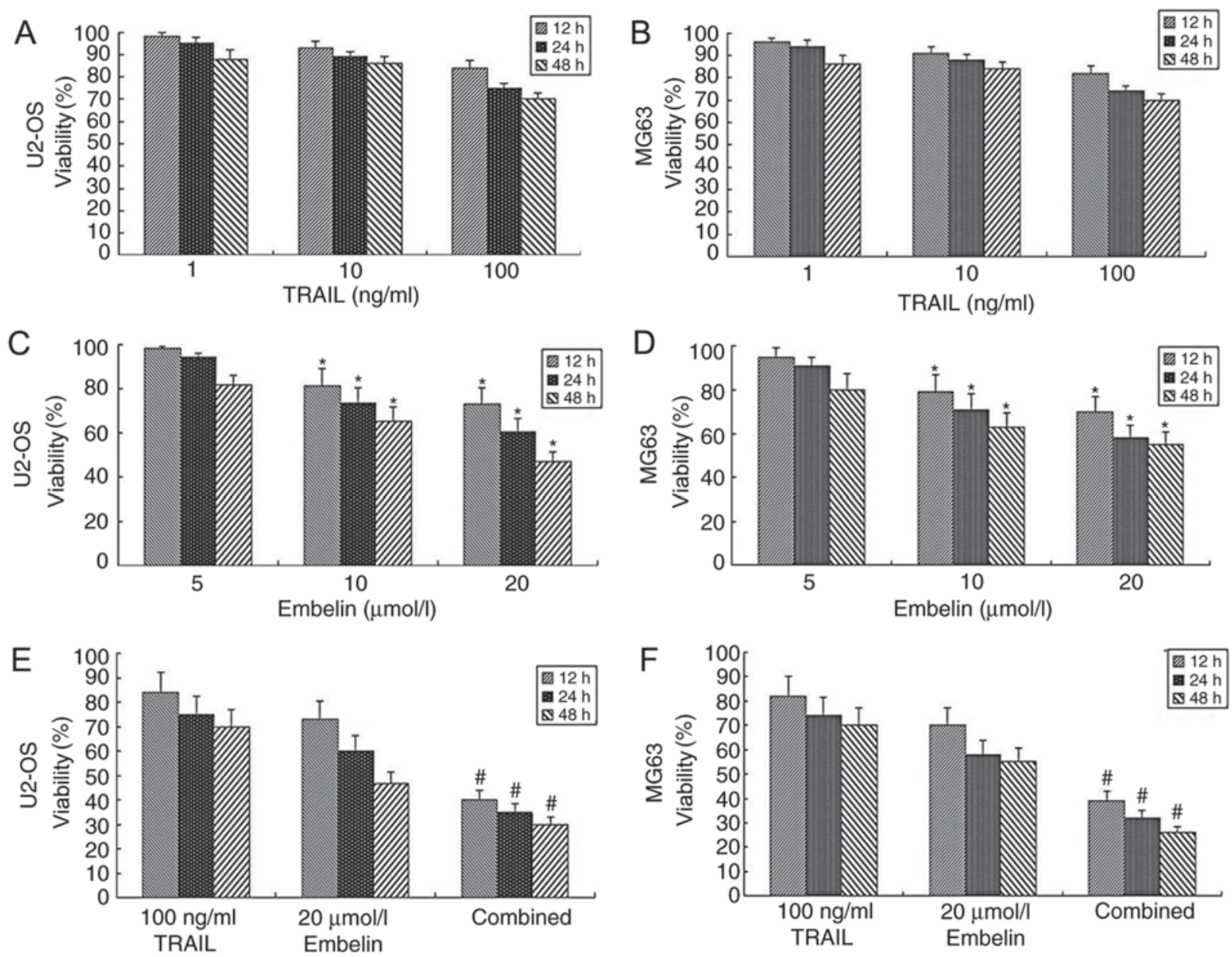

Figure 1. Viability of U2OS and MG63 cells, as measured by MTT after 12, 24 or 48. (A) The viability rate of U2OS cells treated with different concentrations of TRAIL. (B) The viability rate of MG63 cells treated with different concentrations of TRAIL. (C) The viability rate of U2OS cells treated with different concentration of Embelin. (D) The viability rate of MG63 cells treated with different concentration of Embelin. (E) The viability rate of U2OS cells treated with a combination of $100 \mathrm{ng} / \mathrm{ml}$ TRAIL and $20 \mu \mathrm{mol} / 1$ Embelin. (F) The viability rate of MG63 cells treated with a combination of $100 \mathrm{ng} / \mathrm{ml}$ TRAIL and $20 \mu \mathrm{mol} / 1$ Embelin. The data are presented as the mean \pm standard deviation of three independent experiments. ${ }^{*} \mathrm{P}<0.05$ vs. the control group; ${ }^{*} \mathrm{P}<0.01$ vs. the TRAIL group or Embelin group. TRAIL, tumor necrosis factor-related apoptosis-inducing ligand.

monoclonal antibody (dilution, 1:5,000; cat. no. ab181602; Abcam) was used as a control for DR-5, XIAP and MMP-9. The membranes were subsequently washed three times for $30 \mathrm{~min}$ in Tris-buffered saline containing Tween 20 (1xTBST) and were incubated with the horseradish peroxidase-conjugated AffiniPure goat anti-rabbit $\operatorname{IgG}$ secondary antibody (dilution, 1:50,000; cat. no. ab182016; Abcam) diluted with TBST for $2 \mathrm{~h}$ at room temperature, prior to being washed again in TBST three times for $30 \mathrm{~min}$. A BeyoECL Plus kit (Beyotime Institute of Biotechnology) was used to detect protein bands, according to the manufacturer's protocol. MF-Chemisis 2.0 (DNR Bio-Imaging Systems, Ltd., Neve Yamin, Israel) and GelCapture software (version 2.24, DNR Bio-Imaging Systems, Ltd.) were used to obverse and analyze the protein bands $(15,16)$.

Statistical analysis. Statistical analysis was performed using Windows SPSS 17.0 software (SPSS Inc., Chicago, IL, USA). Data are presented as the mean \pm standard deviation of three independent experiments. Data were compared using one-way analysis of variance, followed by the Student-Newman-Keuls test. $\mathrm{P}<0.05$ was considered to indicate a statistically significant difference.

\section{Results}

Viability of tumor cells in the presence of combined TRAIL and Embelin. While concentrations of 1, 10 or $100 \mathrm{ng} / \mathrm{ml}$ TRAIL were used in U2OS or MG63 cells, no significant difference in the dose-inhibiting effect was observed between different groups ( $\mathrm{P}>0.05$; Fig. 1A and $\mathrm{B})$. This observation was consistent with the pre-experimental results. In the pre-experiment, it was revealed that the use of TRAIL alone with concentrations ranging between 0.1 and $1,000 \mathrm{ng} / \mathrm{ml}$ has little effect on U2OS or MG63 cells. As the purpose of the present study was to examine and verify the effect of combined application of Embelin and TRAIL to osteosarcoma cells, appropriate concentrations were selected. When concentrations of $5 \mu \mathrm{mol} / 1$ Embelin were applied to U2OS or MG63 cells at 12,24 or $48 \mathrm{~h}$, no significant difference in the dose-inhibiting effect was observed compared with at $0 \mathrm{~h}$ ( $\mathrm{P}>0.05$; Fig. $1 \mathrm{C}$ and D). However, when concentrations of 10 or $20 \mu \mathrm{mol} / 1$ Embelin were applied to U2OS or MG63 cells, cell viability was inhibited $(\mathrm{P}<0.05$; Fig. $1 \mathrm{C}$ and $\mathrm{D})$. When a combination of $100 \mathrm{ng} / \mathrm{ml}$ TRAIL and $20 \mu \mathrm{mol} / 1$ Embelin was applied to U2OS or MG63 cells, the viability rate was 
A
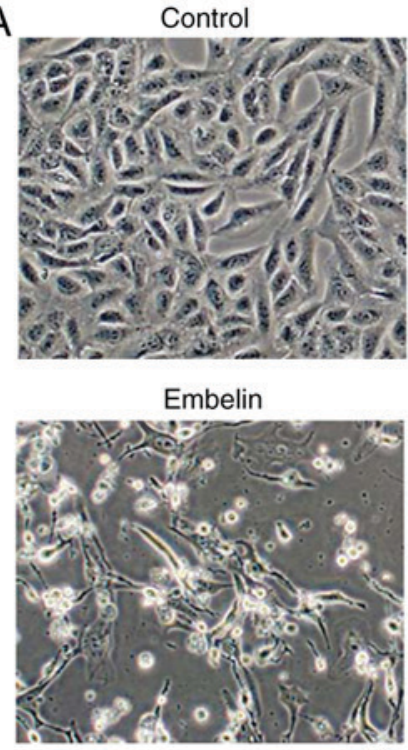

U2-OS

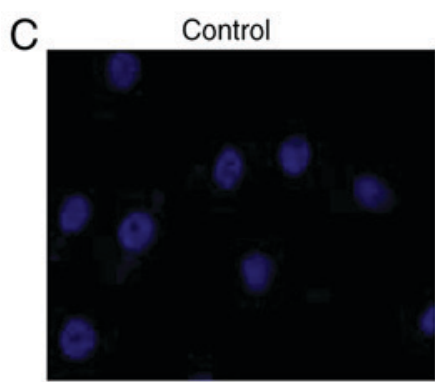

Embelin

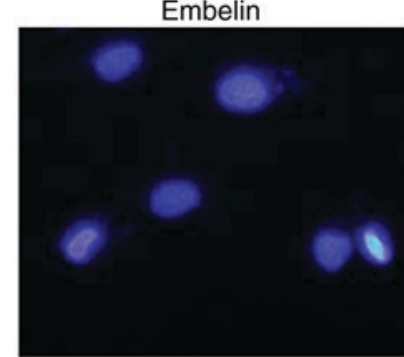

TRAIL

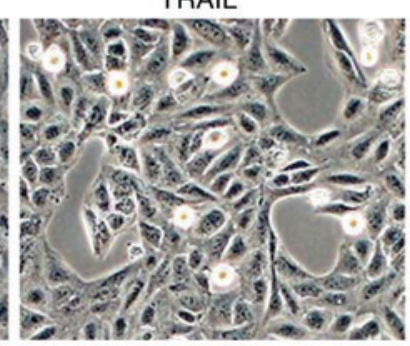

Combined
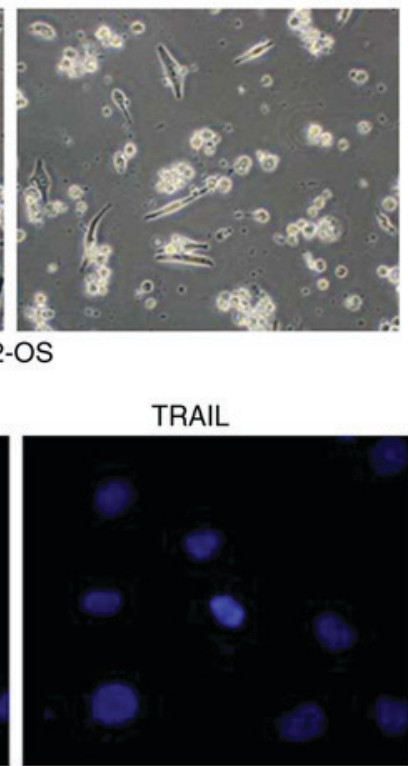

Combined

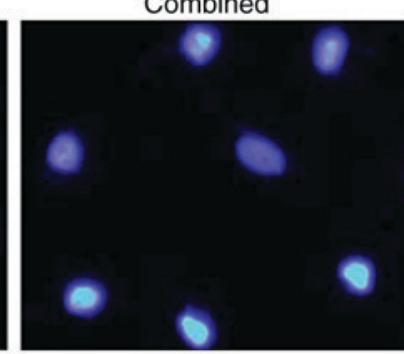

U2-OS

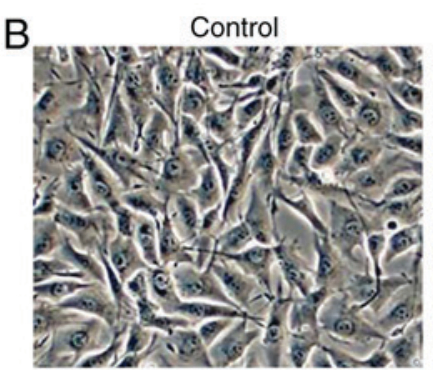

Embelin

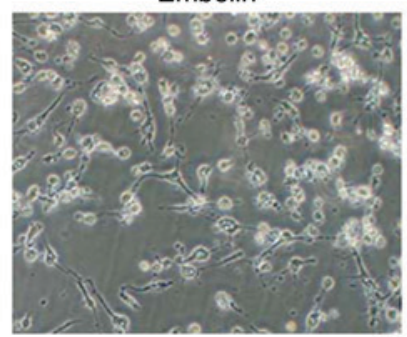

MG63

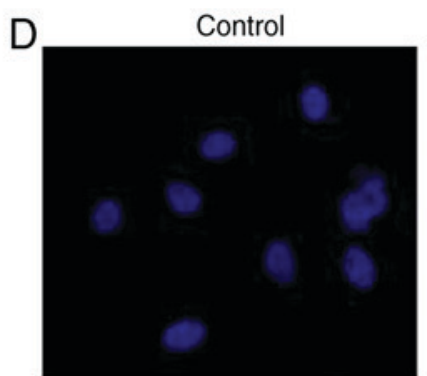

Embelin

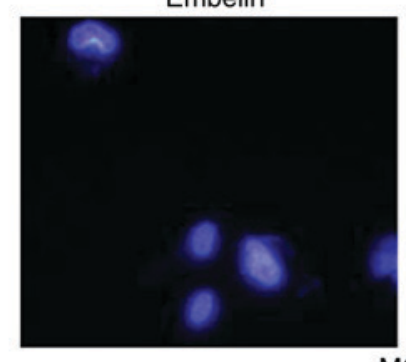

MG63

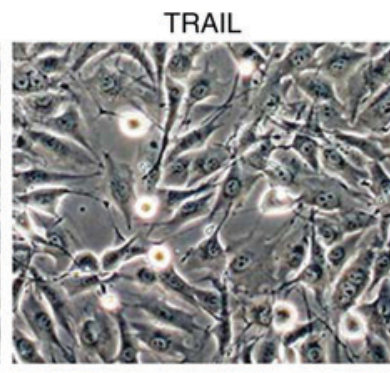

Combined
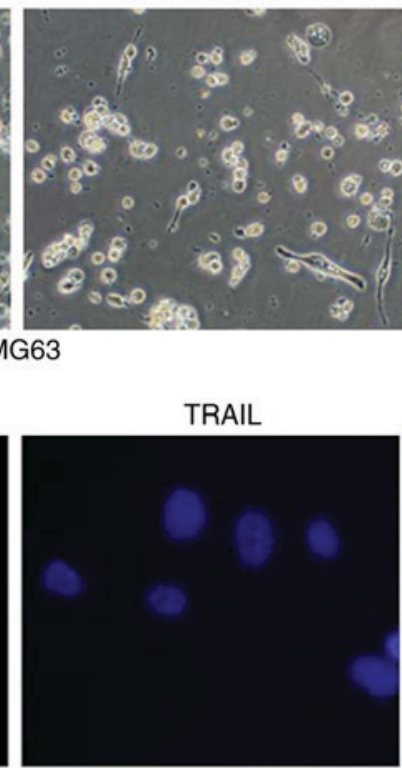

Combined

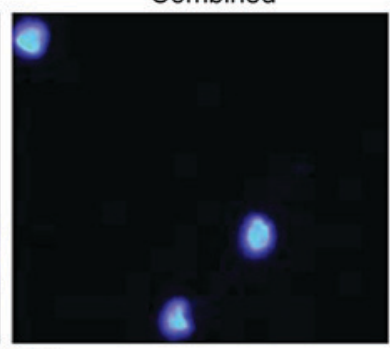

Figure 2. Morphological changes and fluorescent staining of U2OS and MG63 cells treated with different drugs after 48 h. (A) The morphological appearance of U2OS cells (control, treated with $100 \mathrm{ng} / \mathrm{ml}$ TRAIL, treated with $20 \mu \mathrm{mol} / 1$ Embelin or treated with a combination of the two) under an inverted phase contrast microscope. (B) The morphological appearance of MG63 cells (control, treated with $100 \mathrm{ng} / \mathrm{ml}$ TRAIL, treated with $20 \mu \mathrm{mol} / 1$ Embelin or treated with a combination of the two) under an inverted phase contrast microscope. (C) Fluorescent staining of U2OS cells (control, treated with 100 ng/ml TRAIL, treated with $20 \mu \mathrm{mol} / 1$ Embelin or a combination of the two) under a fluorescence microscope. (D) Fluorescent staining of MG63 cells (control, treated with $100 \mathrm{ng} / \mathrm{ml}$ TRAIL, treated with $20 \mu \mathrm{mol} / 1$ Embelin or a combination of the two) under a fluorescence microscope. Magnification, x400. TRAIL, tumor necrosis factor-related apoptosis-inducing ligand.

significantly lower $(\mathrm{P}<0.01)$, compared with the individual treatment groups (Fig. $1 \mathrm{E}$ and F). The results of the present study demonstrated that the combined application of TRAIL and Embelin had a strong inhibitory effect on the viability rates of U2OS and MG63 cells.

Changes in the apoptosis rate of U2OS and MG63 cells. U2OS and MG63 cells were added to the surface of a dish in an angular position (Fig. 2A and B). Following the application of $100 \mathrm{ng} / \mathrm{ml}$ TRAIL or $20 \mu \mathrm{mol} / \mathrm{l}$ Embelin, few of the osteosarcoma cells were small and round (Fig. 2A and B). However, with the combined application of $100 \mathrm{ng} / \mathrm{ml}$ TRAIL and $20 \mu \mathrm{mol} / 1$ Embelin, chromosomes were condensed, and cells became non-adherent and suspended in the DMEM (Fig. 2A and B). Cell death was blocked by joint application of TRAIL and Embelin following the use of $150 \mu \mathrm{M}$ pan-caspase inhibitor z-VAD-fmk or $150 \mu \mathrm{M}$ caspase-8 inhibitor z-IETD-fmk (Fig. 3A and B), which indicated that the process of cell death requires caspases activation. In a field of fluorescence microscope, the majority of U2OS and MG63 cells in the control group were lightly-stained and the morphology of the cells were condensed and exhibited fluorescence (Fig. 2C and D), while in the cells treated with the individual application of $100 \mathrm{ng} / \mathrm{ml}$ TRAIL or $20 \mu \mathrm{mol} / 1$ Embelin, only a small number of cells were lightly-stained and condensed (Fig. 2C and D). With the combined application of 
A
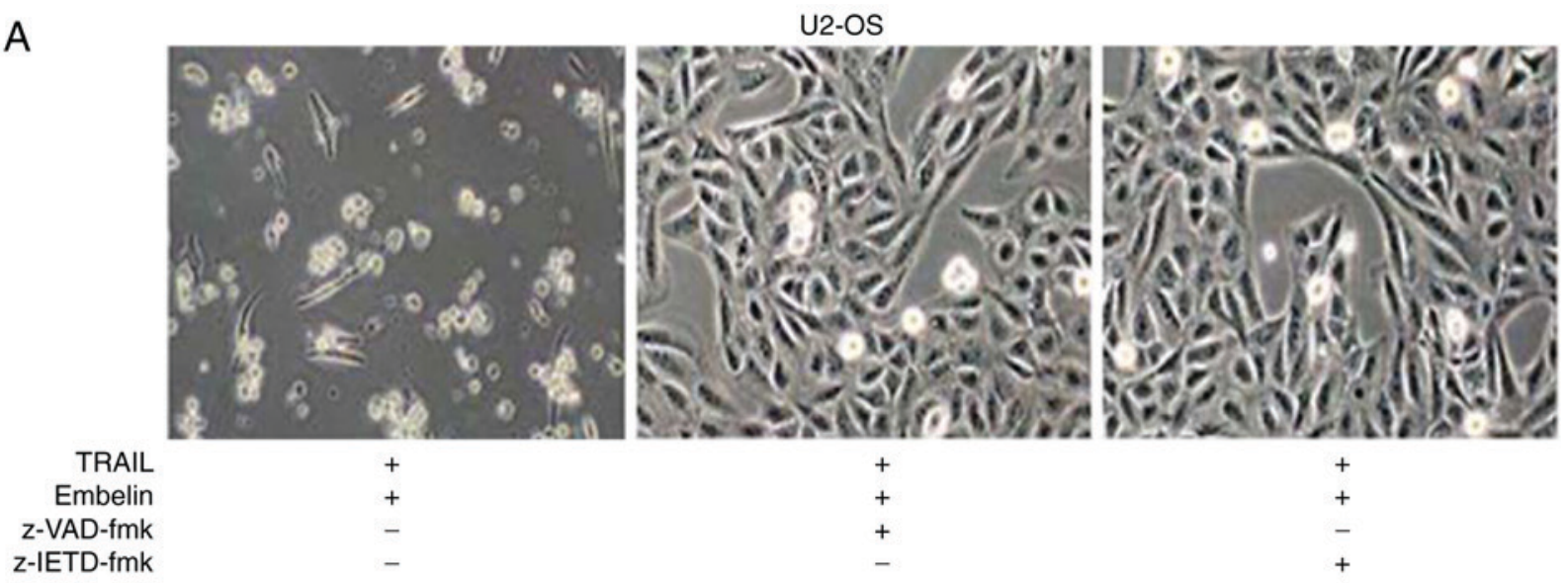

B

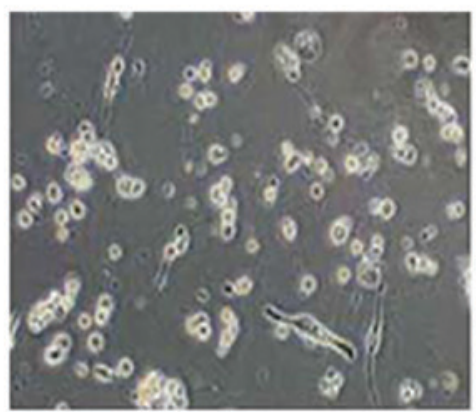

TRAIL
Embelin
z-VAD-fmk
z-IETD-fmk
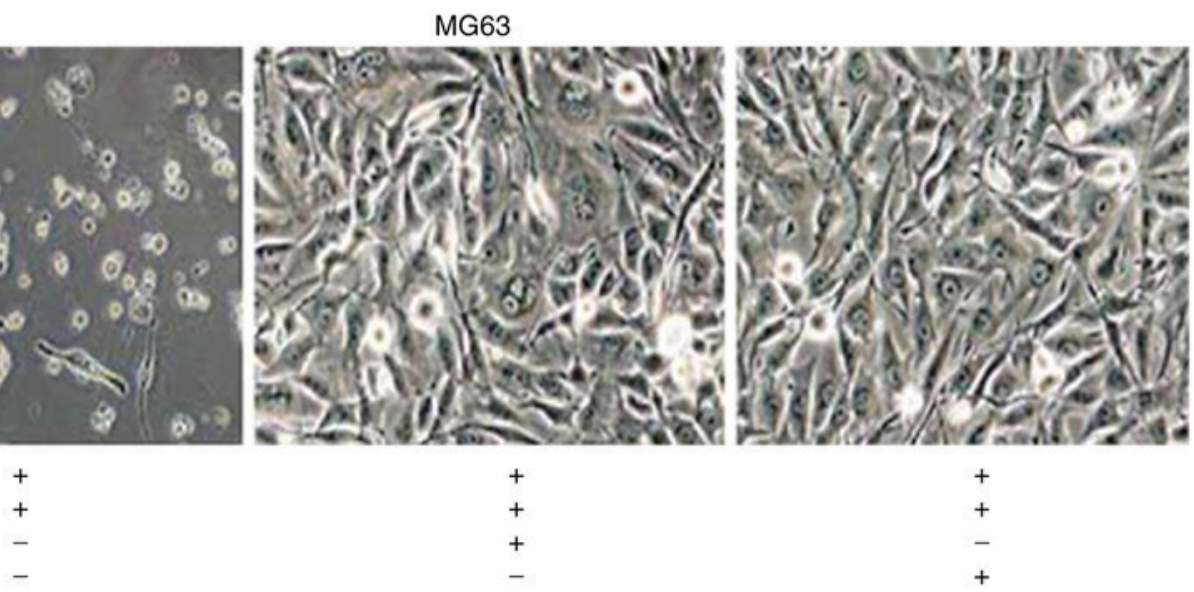

$+$

$+$

$+$

$+$

$+$

Figure 3. Morphological changes of U2OS and MG63 cells under the effects of chemotherapeutic agents after 48 h. (A) U2OS cells was co-treated with $100 \mathrm{ng} / \mathrm{ml}$ TRAIL and $20 \mu \mathrm{mol} / 1$ Embelin in the presence of $150 \mu \mathrm{M} \mathrm{z}$-VAD-fmk or $150 \mu \mathrm{M} \mathrm{z}$-IETD-fmk and images were captured under an inverted phase contrast microscope. (B) MG63 cells were co-treated with $100 \mathrm{ng} / \mathrm{ml}$ TRAIL and $20 \mu \mathrm{mol} / 1$ Embelin in the presence of $150 \mu \mathrm{M} \mathrm{z}$-VAD-fmk or $150 \mu \mathrm{M}$ z-IETD-fmk and images were captured under an inverted phase contrast microscope. Magnification, x400. TRAIL, tumor necrosis factor-related apoptosis-inducing ligand.

$100 \mathrm{ng} / \mathrm{ml}$ TRAIL and $20 \mu \mathrm{mol} / \mathrm{l}$ Embelin, a large number of cells were condensed and exhibited fluorescence, indicating the apoptosis of numerous cells $(\mathrm{P}<0.05)(\mathrm{Fig} .2 \mathrm{C}$ and $\mathrm{D})$.

Effect of Embelin on the invasive ability of U2OS and MG63 cells. The Transwell experiments indicated that the number of U2OS and MG63 cells in the combined treatment group passing through the polycarbonate membrane was significantly less than that in the individual treatment groups and the control group (Fig. 4A and B). Cells that were able to invade to the lower side of the membrane in the Transwell assays after 24-h incubation were quantified (Fig. 4C and D). These data indicated that the combined application of TRAIL and Embelin may diminish the invasion of U2OS and MG63 cell lines more significantly than the individual application of either treatment.

Effect of Embelin on the apoptosis of U2OS and MG63 cells. Annexin V and PI staining experiment results demonstrated that, with the combined application of $100 \mathrm{ng} / \mathrm{ml}$ TRAIL and $20 \mu \mathrm{mol} / \mathrm{l}$ Embelin, the number of apoptotic cells was more than that in the control group and the individual treatment groups $(\mathrm{P}<0.01$; Fig. 5). As Annexin V and PI staining results demonstrated in Fig. 5A, the early apoptotic rates of the control group, the TRAIL-only group, the Embelin-only group and the combined treatment group in U2OS cells were $0.73,3.54$, 12.33 and $20.71 \%$, respectively. The late apoptotic rates in U2OS cells were $1.87,6.12,6.82$ and $10.84 \%$, respectively, and the total apoptotic rates in U2OS cells were 2.60, 9.66, 19.15 and $31.55 \%$, respectively. A similar trend was also observed in the MG63 cells (Fig. 5B). The early apoptotic rates of the control group, the TRAIL-only group, the Embelin-only group and the combined treatment group in MG63 cells were 0.94, $3.51,5.76$ and $10.17 \%$, respectively, the late apoptotic rates in MG63 cells were $2.43,4.18,10.64$ and $15.14 \%$, respectively, and the total apoptotic rates in MG63 cells were 3.37, 7.33, 16.40 and $25.31 \%$, respectively. These data indicated that the combined treatment may increase the apoptosis rate of U2OS and MG63 cells, compared with individual treatment with either drug (Fig. 5C and D).

The expression of caspase-3, caspase-8, cleaved caspase-3, DR5, XIAP and MMP-9 in U2OS cells. Following exposure to $100 \mathrm{ng} / \mathrm{ml}$ TRAIL, $20 \mu \mathrm{mol} / 1$ Embelin or the combined application of the two for $48 \mathrm{~h}$, expression levels of caspase- 3 , caspase- 8 , cleaved caspase 3, DR5, XIAP and MMP-9 in U2OS cells were 

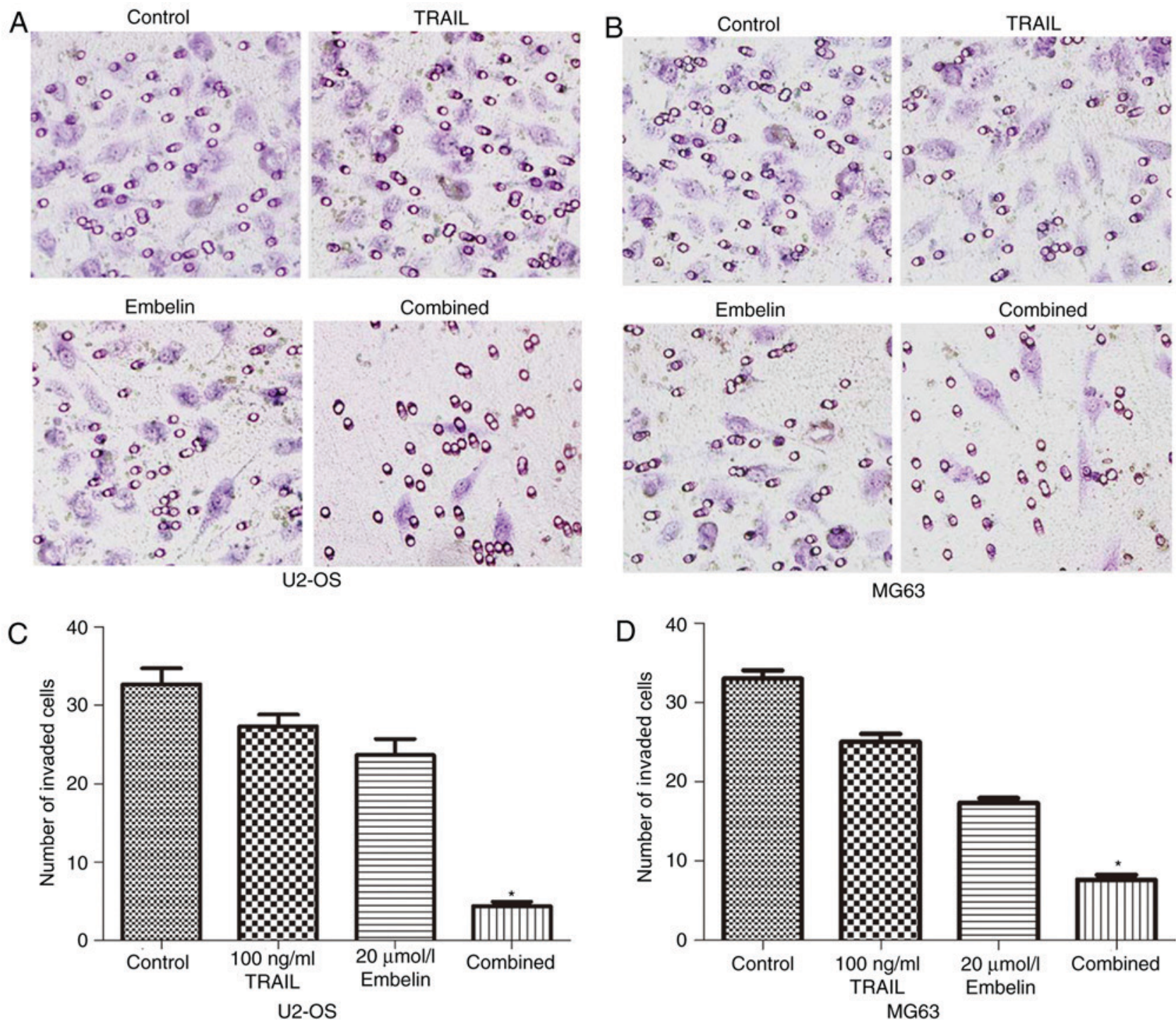

Figure 4. Invasion in U2OS and MG63 cells treated with different drugs after $24 \mathrm{~h}$. (A) Crystal violet staining of the U2OS cells (control, treated with $100 \mathrm{ng} / \mathrm{ml}$ TRAIL, treated with $20 \mu \mathrm{mol} / 1$ Embelin or treated with a combination of the two) that passed through the polycarbonate membrane under an inverted phase contrast microscope. (B) The crystal violet staining of the MG63 cells (control, treated with $100 \mathrm{ng} / \mathrm{ml}$ TRAIL, treated with $20 \mu$ mol/1 Embelin or treated with a combination of the two) that passed through the polycarbonate membrane under an inverted phase contrast microscope. (C) Quantification of U2OS cells that had attached to the basal side of the membrane. (D) Quantification of MG63 cells that had attached to the basal side of the membrane. Data are presented as the mean \pm standard deviation of three independent experiments. Magnification, $\mathrm{x} 400 .{ }^{*} \mathrm{P}<0.05$ vs. the control group. TRAIL, tumor necrosis factor-related apoptosis-inducing ligand.

measured using western blot analysis in the present study. The levels of caspase-3, caspase-8, cleaved caspase 3 and DR5 in the combined treatment group were significantly higher than that of the individual treatment groups and the control group $(\mathrm{P}<0.05)$. By contrast, levels of XIAP and MMP-9 in the combined treatment group were significantly lower than in the individual treatments groups and the control group $(\mathrm{P}<0.05)$ (Fig. 6).

\section{Discussion}

TRAIL is a member of the TNF super family of cytokines $(17,18)$. TRAIL is a potentially important anticancer agent, since it selectively kills malignant cells while leaving normal cells unaffected $(19,20)$. TRAIL induces apoptosis through interactions with its death domain containing receptors DR4 and DR5 $(21,22)$. Once activated, TRAIL receptors recruit Fas-associated protein with death domain as a major cellular adaptor protein, which triggers the auto-activation of caspase- 8 and subsequently leads to the activation of downstream caspases, including caspases-3, -7 and -9 . This resulted in the cleavage of cellular substrates and ultimately cell death. However, certain tumor cells, including gastric, hepatic, lung and osteosarcoma cells are not sensitive to TRAIL (23-26). The present study also demonstrated that there was no significant difference in the viability rate of U2OS and MG63 cells between the TRAIL group and the control group, which confirmed the tolerance of U2OS and MG63 cells to TRAIL (Fig. 1A). Although previous studies have revealed that the combination of TRAIL and certain chemotherapy drugs may improve the sensitivity of osteosarcoma cells to TRAIL $(27,28)$, to a certain extent, such treatment regimens continue to depend upon chemotherapy drugs and side effects to healthy cells are inevitable. Therefore, identifying a treatment 

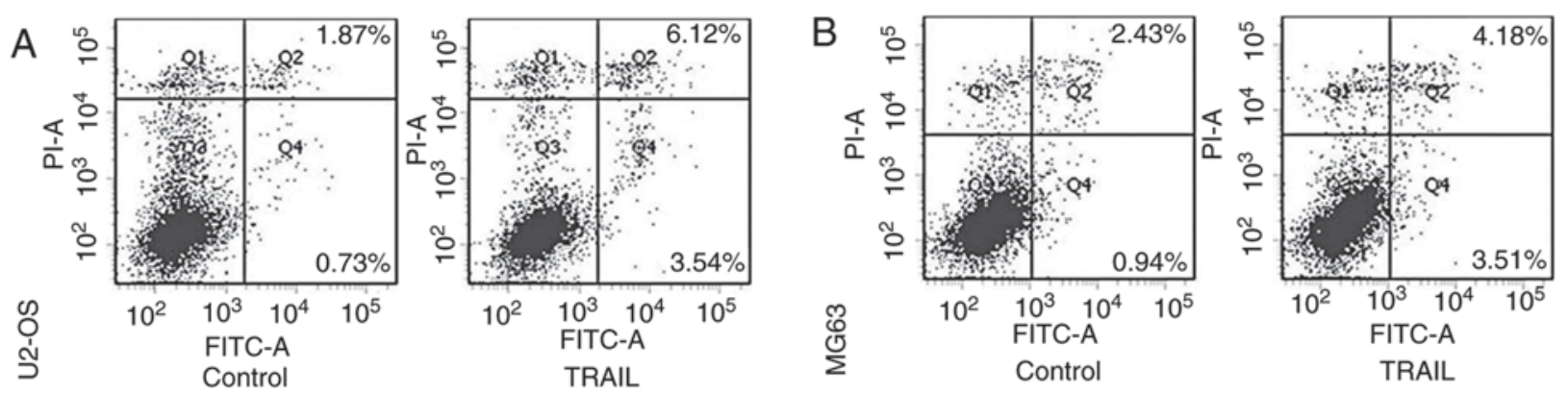
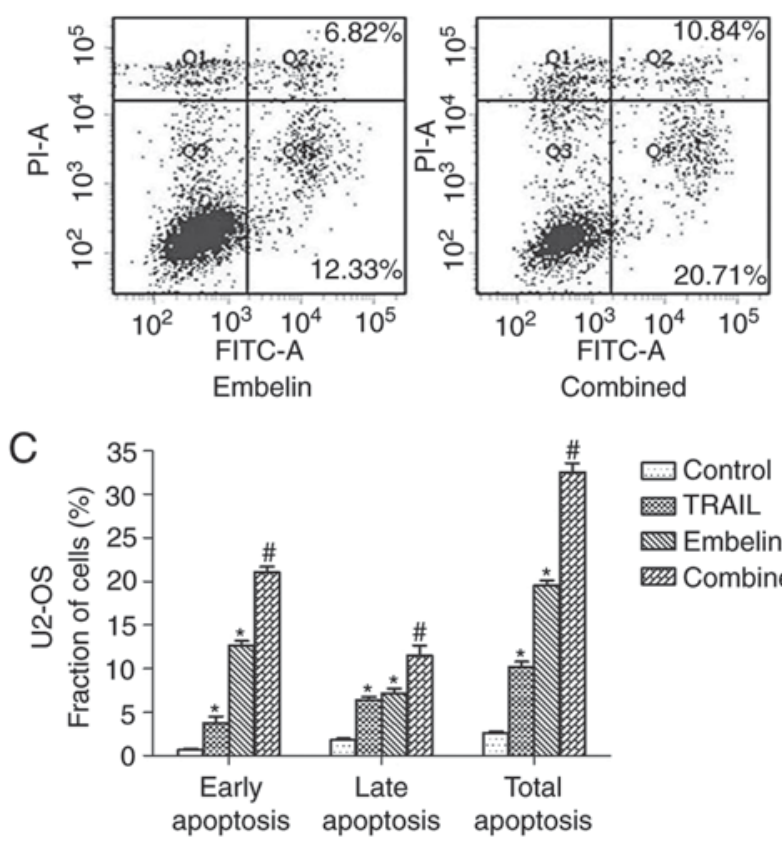
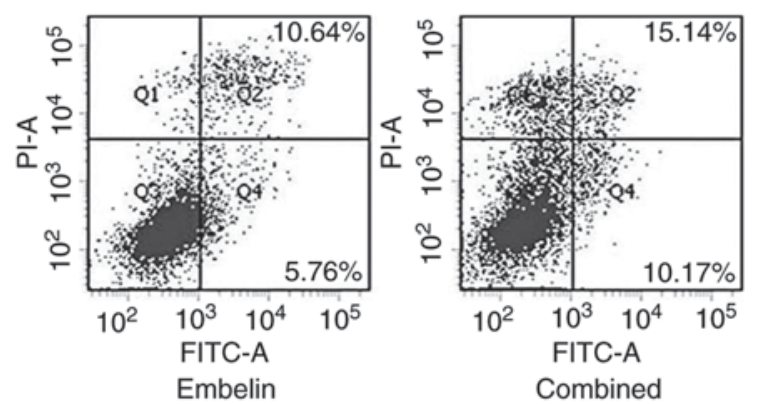

$\mathrm{D}$

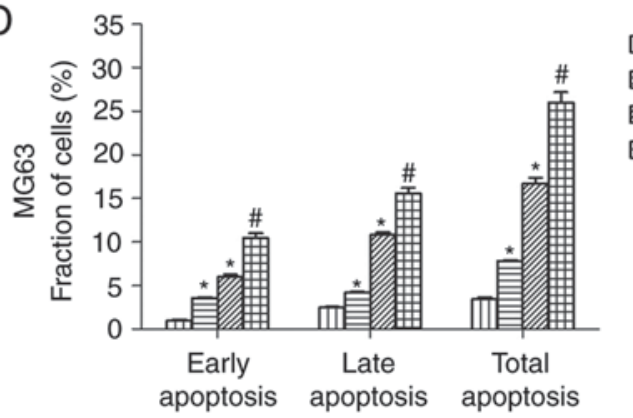

Figure 5. Apoptosis in U2OS and MG63 cells treated with different drugs after 24 h. The four groups of (A) U2OS and (B) MG63 cells (control, treated with $100 \mathrm{ng} / \mathrm{ml}$ TRAIL, treated with $20 \mu \mathrm{mol} / 1$ Embelin or treated with a combination of the two) were incubated for $24 \mathrm{~h}$. Cells stained with FITC-conjugated Annexin V and PI were analyzed by flow cytometric analysis. In the lower right quadrant, early apoptotic cells were observed, and the necrotic or late apoptotic cells were located in the upper right quadrant. The percentage of early apoptotic, late apoptotic and total apoptotic (C) U2OS and (D) MG63 cells (control, treated with $100 \mathrm{ng} / \mathrm{ml}$ TRAIL, treated with $20 \mu \mathrm{mol} / 1$ Embelin or treated with a combination of the two) for $24 \mathrm{~h}$. Data are presented as the mean \pm standard deviation of three independent experiments. ${ }^{*} \mathrm{P}<0.01$ vs. control group; ${ }^{*} \mathrm{P}<0.01 \mathrm{vs}$. TRAIL group or Embelin group. TRAIL, tumor necrosis factor-related apoptosis-inducing ligand; FITC, fluorescein isothiocyanate; PI, propidium iodide.

plan regarding TRAIL that has fewer side effects has become an aim for numerous researchers worldwide (29). Recent studies regarding biologically targeted therapy have revealed that the function of TRAIL in conducting the death signal into cells may be doubled by the high expression of DR4 or DR5 (30,31). Such studies may speed up the advancement in application of TRAIL in the treatment of osteosarcoma and have become a hot topic. Therefore, the aim of the present study was to identify a drug that may be used in combination with TRAIL to reduce the resistance of osteosarcoma cells to TRAIL by activating DR4 or DR5.

XIAP is one of the best characterized and most potent endogenous inhibitors of the caspases and is therefore considered a key physiological regulator of cell death $(5,6)$. XIAP inhibits the upstream caspase- 9 by binding it to its BIR3 domain, and the downstream caspase-3 and caspase-7 by binding them to its BIR2 domain. XIAP expression is elevated in numerous types of cancer including lung, ovarian, colon and kidney cancer, and myeloid leukemia, which was also responsible for resistance to chemotherapy (32). Embelin was identified $\sim 50$ years ago as an active component of the
Embelia ribes BURM (33). Myrsinaceae, which has been used as traditional medicine for thousands of years to treat a diverse range of illnesses, including fever, inflammatory diseases and various gastrointestinal ailments and therefore, must pose a low toxicity threat (34). Until recently, Embelin has been regarded as an inhibitor of XIAP to induce the proliferation suppression and apoptosis of human cancer cells in various organs, including pancreatic, colon and prostate cancer, as well as leukemia (35-37). At, present, to the best of our knowledge, no reports have stated that Embelin inhibited the proliferation and invasion of osteosarcoma cells. Furthermore, a recent study demonstrated that Embelin may upregulate the expression of DR4 or DR5, and increase the susceptibility of tumor cells to TRAIL (38). In our pre-experiment, it was revealed that Embelin posed a killing effect on osteosarcoma cells and, based on this, further research was performed to investigate whether or not Embelin may enhance the TRAIL-DR5 pathway, thereby increasing the sensitivity of osteosarcoma cells in order to identify a novel strategy for the use of TRAIL.

The results of the present study suggested that the combined application of TRAIL and Embelin had a synergistic apoptotic 

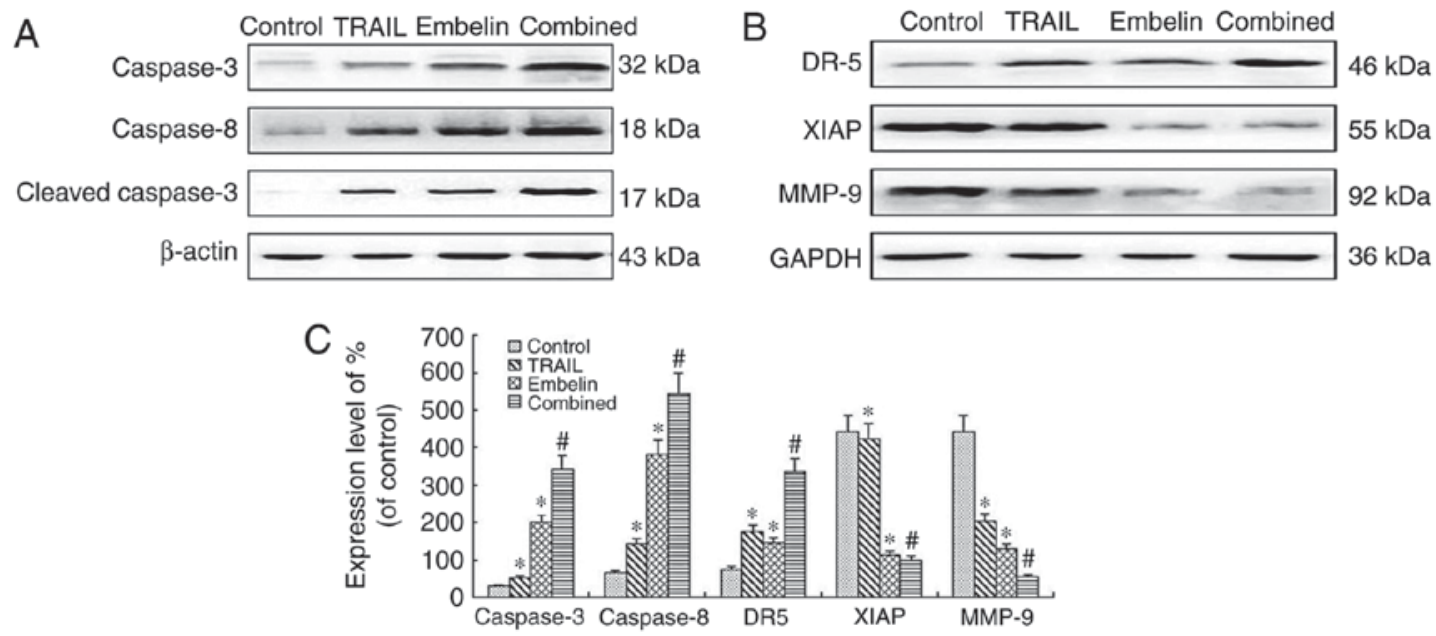

Figure 6. Western blot analysis of the expression of proteins after U2OS cells were cultured for $48 \mathrm{~h}$. (A) The levels of caspase-3 (32 kDa), caspase-8 (18 kDa) and cleaved caspase-3 (17 kDa) were analyzed by western blot analysis. There was a marked increase in the expression of caspase-3, cleaved caspase-3, caspase- 8 in the combined treatment group, P<0.01. (B) The levels of XIAP (55 kDa), MMP-9 (92 kDa) and DR5 (46 KDa) were analyzed by western blot analysis. There was a marked downregulation in the expression of XIAP and MMP-9 in the combined treatment group, P $<0.01$. However, there was a marked upregulation in the expression of DR5 in the combination group, $\mathrm{P}<0.01$. (C) Quantification of relative protein expression. Data are presented as the mean \pm standard deviation of three independent experiments. ${ }^{*} \mathrm{P}<0.01$ vs. control group; $\mathrm{P}<0.01$ vs. TRAIL group or Embelin group. TRAIL, tumor necrosis factor-related apoptosis-inducing ligand; XIAP, X-linked inhibitor of apoptosis protein; MMP-9, matrix metalloproteinase 9; DR5, death receptor 5.

effect compared with that of the individual application of either treatment. The results of the MTT assay demonstrated that combined treatment had a stronger inhibitory effect on the viability rate of U2OS and MG63 cells compared with the individual application of either agent (Fig. 1). Furthermore, combined treatment caused more distinct morphological changes compared with the application of each agent individually (Fig. 2). The present study also demonstrated that the killing effect of the combined treatment was achieved by inducing the apoptosis of osteosarcoma cells, as revealed by Hoechst staining (Fig. 2C and D). Furthermore, Annexin V and PI staining results indicated that the combined application of TRAIL and Embelin also served an important role in the apoptotic effect on osteosarcoma cells (Fig. 5). The apoptosis-induced effects on the combined treatment group were much stronger than that of the individual treatment groups and the control group. These results are consistent with those of previous studies on other types of tumor cell (39). The results of the Transwell invasion chamber experiments revealed that the inhibition of invasion in the combined treatment group was more significant than that in the control group and the individual treatment groups (Fig. 4A and B). Furthermore, the expression of MMP-9, which is well known to be the most important indicator of invasion ability (40), was significantly lower in the combined treatment group than in the control group and the individual treatment groups (Fig. 6B). All these results revealed that the combination of Embelin and TRAIL may inhibit the invasion of osteosarcoma cells. Similarly to the change in MMP-9 expression, the expression of XIAP was also downregulated due to the inhibitory effects of the treatment with Embelin (Fig. 6B). In addition, the combination of the two treatments upregulated the expression of DR5, cleaved-caspase-3 and caspase-8 (Fig. 6A and B). The total caspase- 3 expression and the cleaved-caspase- 3 expression were also increased. Based on the aforementioned results, the mechanism through which Embelin enhances TRAIL-induced apoptosis of osteosarcoma may be that Embelin upregulates the expression of DR5, thereby increasing the susceptibility of osteosarcoma cells to TRAIL, and that Embelin inhibits the expression of XIAP, which may upregulate the expression of caspases. These two pathways eventually result in the apoptosis of osteosarcoma cells.

Despite the fact that a number of studies have reported that the combination of Embelin and TRAIL induced the apoptosis of cancer cells, the results of the present study exhibit certain differences. Yang et al (41) demonstrated that Embelin inhibited the LMP1-mediated upregulation of XIAP and TRAIL resistance in nasopharyngeal carcinoma cells. The combined application of Embelin and TRAIL are limited to nasopharyngeal carcinoma cells overexpressing LMP1 proteins. In the present study, the combined application of Embelin and TRAIL were not limited to any over-expressing protein. The study of Yang et al (42) revealed that the underlying mechanism through which combined application of Embelin and TRAIL suppresses the NF- $\kappa \mathrm{B}$-dependent survival pathway in human acute myeloid leukemia cells. By contrast, the present study suggested that Embelin enhanced the TRAIL-induced apoptosis of osteosarcoma cells via the activation of the TRAIL-DR5-caspase signal pathway. By contrast, the indicators and methods used in the present study are similar to those used in a previously study that employed Embelin as a small-molecule inhibitor of XIAP to induce the apoptosis of tumor cells and restore the sensitivity of non-small cell lung cancer cells to TRAIL (38). However, in the present study, the therapeutic effect of Embelin on the TRAIL-induced apoptosis of osteosarcoma cells was investigated.

In conclusion, the results of the present study suggested that the XIAP inhibitor Embelin enhanced the TRAIL-induced apoptosis and inhibited the invasion of osteosarcoma cells, which may be related to the activation of the TRAIL-DR5-caspase signal pathway. Therefore, Embelin may sensitize osteosarcoma cells to TRAIL and alleviate the toxic side effects of the chemotherapy drug on the human body and therefore, the 
combination of TRAIL and Embelin may be a promising treatment for patients with osteosarcoma. However, XIAP siRNA and in vivo experiments are required in order to further validate the results of the present study. Since B cell lymphoma 2 (Bcl-2) family proteins serve an important role in Embelin-enhanced TRAIL-induced cell apoptosis, whether or not caspase-induced apoptosis depends on Bcl-2 requires further investigation.

\section{Acknowledgements}

Not applicable.

\section{Funding}

The present study was supported by the Science and Technology Department of Liaoning Province (grant no. 2013225021), the Science and Technology Department of Shenyang City (grant no. F14-231-1-48).

\section{Availability of data and materials}

All data and materials described in the manuscript are available upon reasonable request from the corresponding author.

\section{Authors' contributions}

TH conceived and designed the experiments, HQ and YC performed the experiments; HQ, XL and WZ wrote the paper; TL and GJ performed the western blot analysis, SC and PL helped perform the analysis. All authors read and approved the manuscript.

\section{Ethics approval and consent to participate}

Not applicable.

\section{Consent for publication}

Not applicable.

\section{Competing interest}

The authors declare that they have no competing interests.

\section{References}

1. Rasalkar DD, Chu WC, Lee V, Paunipagar BK, Cheng FW and Li CK: Pulmonary metastases in children with osteosarcoma: Characteristics and impact on patient survival. Pediatr Radiol 41: 227-236, 2011.

2. Li X, Huang T, Jiang G, Gong W, Qian H and Zou C: Proteasome inhibitor MG132 enhances TRAIL-induced apoptosis and inhibits invasion of human osteosarcoma OS732 cells. Biochem Biophys Res Commun 439: 179-186, 2013.

3. Somasekharan SP, Koc M, Morizot A, Micheau O, Sorensen PH, Gaide O, Andera L and Martinou JC: TRAIL promotes membrane blebbing, detachment and migration of cells displaying a dysfunctional intrinsic pathway of apoptosis. Apoptosis 18: 324-336, 2013.

4. Ng CP, Zisman A and Bonavida B: Synergy is achieved by complementation with Apo2L/TRAIL and actinomycin D in Apo2L/TRAIL-mediated apoptosis of prostate cancer cells: Role of XIAP in resistance. Prostate 53: 286-299, 2002.
5. Gillissen B, Richter A, Richter A, Overkamp T, Essmann F, Hemmati PG, Preissner R, Belka C and Daniel PT: Targeted therapy of the XIAP/proteasome pathway overcomes TRAIL-resistance in carcinoma by switching apoptosis signaling to a Bax/Bak-independent 'type I' mode. Cell Death Dis 4: e643, 2013.

6. Fakler M, Loeder S, Vogler M, Schneider K, Jeremias I, Debatin KM and Fulda S: Small molecule XIAP inhibitors cooperate with TRAIL to induce apoptosis in childhood acute leukemia cells and overcome Bcl-2-mediated resistance. Blood 113: 1710-1722, 2009.

7. Tnah LH, Lee CT, Lee SL, Ng CH and Ng KK: Development of microsatellites in Labisia pumila (Myrsinaceae), an economically important Malaysian herb. Appl Plant Sci 2: pii: apps.1400019, 2014.

8. Ndontsa BL, Tchinda A, Teponno RB, Mpetga JS, Frédérich M and Tane P: Ardisikivuoside, a new triterpenoid saponin from Ardisia kivuensis (Myrsinaceae). Nat Prod Commun 7: 515-516, 2012.

9. Karimi E, Jaafar HZ, Aziz MA, Taheri S and AzadiGonbad R: Genetic relationship among Labisia pumila (Myrsinaceae) species based on ISSR-PCR. Genet Mol Res 13: 3301-3309, 2014.

10. Allensworth JL, Aird KM, Aldrich AJ, Batinic-Haberle I and Devi GR: XIAP inhibition and generation of reactive oxygen species enhances TRAIL sensitivity in inflammatory breast cancer cells. Mol Cancer Ther 11: 1518-1527, 2012.

11. Li X, Huang T, Jiang G, Gong W, Qian H and Zou C: Synergistic apoptotic effect of crocin and cisplatin on osteosarcoma cells via caspase induced apoptosis. Toxicol Lett 221: 197-204, 2013.

12. Kong Y, Yin J, Cheng D, Kong Y, Yin J, Cheng D, Lu Z, Wang N, Wang F and Liang M: Antithrombin III attenuates AKI following acute severe pancreatitis. Shock, Jul 17, 2017 (Epub ahead of print).

13. Song F, Wang H and Wang Y: Myeloid ecotropic viral integration site 1 inhibits cell proliferation, invasion or migration in human gastric cancer. Oncotarget 8: 90050-90060, 2017.

14. Zou J, Zhang W and Li XL: Effects of SOST gene silencing on proliferation, apoptosis, invasion, and migration of human osteosarcoma cells through the $\mathrm{Wnt} / \beta$-catenin signaling pathway. Calcif Tissue Int 100: 551-564, 2017.

15. Mahmood T and Yang PC: Western blot: Technique, theory, and trouble shooting. N Am J Med Sci 4: 429-434, 2012.

16. Lu Z, Cheng D, Yin J, Wu R, Zhang G, Zhao Q, Wang N, Wang F and Liang M: Antithrombin III protects against contrast-induced nephropathy. EBioMedicine 17: 101-107, 2017.

17. Moon MH, Jeong JK, Seo JS, Seol JW, Lee YJ, Xue M, Jackson CJ and Park SY: Bisphosphonate enhances TRAIL sensitivity to human osteosarcoma cells via death receptor 5 upregulation. Exp Mol Med 43: 138-145, 2011.

18. Srinivasan S, Kumar R, Koduru S, Chandramouli A and Damodaran C: Inhibiting TNF-mediated signaling: A novel therapeutic paradigm for androgen independent prostate cancer. Apoptosis 15: 153-161, 2010.

19. Voelkel-JohnsonC: Anantibody againstDR4(TRAIL-R1)incombination with doxorubicin selectively kills malignant but not normal prostate cells. Cancer Biol Ther 2: 283-290, 2003.

20. Newsom-Davis T, Prieske S and Walczak H: Is TRAIL the holy grail of cancer therapy? Apoptosis 14: 607-623, 2009.

21. Mitsiades CS, Treon SP, Mitsiades N, Shima Y, Richardson P, Schlossman R, Hideshima T and Anderson KC: TRAIL/Apo2L ligand selectively induces apoptosis and overcomes drug resistance in multiple myeloma: Therapeutic applications. Blood 98: 795-804, 2001.

22. Locklin RM, Federici E, Espina B, Hulley PA, Russell RG and Edwards CM: Selective targeting of death receptor 5 circumvents resistance of MG-63 osteosarcoma cells to TRAIL-induced apoptosis. Mol Cancer Ther 6: 3219-3228, 2007.

23. Wang WQ, Zhang H, Wang HB, Sun YG, Peng ZH, Zhou G, Yang SM, Wang RQ and Fang DC: Programmed cell death 4 (PDCD4) enhances the sensitivity of gastric cancer cells to TRAIL-induced apoptosis by inhibiting the PI3K/Akt signaling pathway. Mol Diagn Ther 14: 155-161, 2010.

24. von Pawel J, Harvey JH, Spigel DR, Dediu M, Reck M, Cebotaru CL, Humphreys RC, Gribbin MJ, Fox NL and Camidge DR: Phase II trial of mapatumumab, a fully human agonist monoclonal antibody to tumor necrosis factor-related apoptosis-inducing ligand receptor 1 (TRAIL-R1), in combination with paclitaxel and carboplatin in patients with advanced non-small-cell lung cancer. Clin Lung Cancer 15: 188-196.e2, 2014. 
25. Zheng SJ, Wang P, Tsabary G and Chen YH: Critical roles of TRAIL in hepatic cell death and hepatic inflammation. J Clin Invest 113: 58-64, 2004.

26. Garnett TO, Filippova M and Duerksen-Hughes PJ: Bid is cleaved upstream of caspase- 8 activation during TRAIL-mediated apoptosis in human osteosarcoma cells. Apoptosis 12: 1299-1315, 2007.

27. Yang DS, Miao XD, Ye ZM and Xu YS: Synergistic induction of apoptosis by the combination of TRAIL and low dose adriamycin in human osteosarcoma cell line U2OS. Zhonghua Zhong Liu Za Zhi 27: 595-597, 2005 (In Chinese).

28. Wu J, Zeng T, Wu X, Gao Q, Zhai W and Ding Z: Ether à go-go 1 silencing in combination with TRAIL overexpression has synergistic antitumor effects on osteosarcoma. Cancer Biother Radiopharm 28: 65-70, 2013.

29. Lanuti P, Bertagnolo V, Pierdomenico L, Bascelli A, Santavenere E, Alinari L, Capitani S, Miscia S and Marchisio M: Enhancement of TRAIL cytotoxicity by AG-490 in human ALL cells is characterized by downregulation of cIAP-1 and cIAP-2 through inhibition of Jak2/Stat3. Cell Res 19: 1079-1089, 2009.

30. Ren YG, Wagner KW, Knee DA, Aza-Blanc P, Nasoff M and Deveraux QL: Differential regulation of the TRAIL death receptors DR4 and DR5 by the signal recognition particle. Mol Biol Cell 15: 5064-5074, 2004.

31. Schneider P, Thome M, Burns K, Bodmer JL, Hofmann K, Kataoka T, Holler N and Tschopp J: TRAIL receptors 1 (DR4) and 2 (DR5) signal FADD-dependent apoptosis and activate NF-kappaB. Immunity 7: 831-836, 1997.

32. Yin D, Wang N, Zhang SL, Jiang Y, Lu YM, Wei H, Huo NC, Xiao Q and Ou YL: Specific siRNA inhibits XIAP expression in human endometrial carcinoma cell apoptosis. Cell Biochem Biophys 71: 161-165, 2015.

33. Poojari R: Embelin-a drug of antiquity: Shifting the paradigm towards modern medicine. Expert Opin Investig Drugs 23: 427-444, 2014

34. Cragg GM, Newman DJ and Yang SS: Natural product extracts of plant and marine origin having antileukemia potential. The NCI experience. J Nat Prod 69: 488-498, 2006.
35. Dai Y, Qiao L, Chan KW, Yang M, Ye J, Ma J, Zou B, Gu Q, Wang J, Pang R, et al: Peroxisome proliferator-activated receptor-gamma contributes to the inhibitory effects of Embelin on colon carcinogenesis. Cancer Res 69: 4776-4783, 2009.

36. Hu R, Zhu K, Li Y, Yao K, Zhang R, Wang H, Yang W and Liu Z: Embelin induces apoptosis through down-regulation of XIAP in human leukemia cells. Med Oncol 28: 1584-1588, 2011.

37. Marsh JL, Jackman CP, Tang SN, Shankar S and Srivastava RK: Embelin suppresses pancreatic cancer growth by modulating tumor immune microenvironment. Front Biosci (Landmark Ed) 19: 113-125, 2014.

38. Jiang L, Hao JL, Jin ML, Zhang YG and Wei P: Effect of Embelin on TRAIL receptor $2 \mathrm{mAb}$-induced apoptosis of TRAIL-resistant A549 non-small cell lung cancer cells. Asian Pac J Cancer Prev 14: 6115-6120, 2013.

39. Hu R, Yang Y, Liu Z, Jiang H, Zhu K, Li J and Xu W: The XIAP inhibitor Embelin enhances TRAIL-induced apoptosis in human leukemia cells by DR4 and DR5 upregulation. Tumour Biol 36: 769-777, 2015.

40. Lu S, Zhang Z, Chen M, Li C, Liu L and Li Y: Silibinin inhibits the migration and invasion of human gastric cancer SGC7901 cells by downregulating MMP-2 and MMP-9 expression via the p38MAPK signaling pathway. Oncol Lett 14: 7577-7582, 2017.

41. Yang S, Li SS, Yang XM, Yin DH and Wang L: Embelin prevents LMP1-induced TRAIL resistance via inhibition of XIAP in nasopharyngeal carcinoma cells. Oncol Lett 11: 4167-4176, 2016.

42. Yang T, Lan J, Huang Q, Chen X, Sun X, Liu X, Yang P, Jin T, Wang S and Mou X: Embelin sensitizes acute myeloid leukemia cells to TRAIL through XIAP inhibition and NF- $\kappa$ B inactivation. Cell Biochem Biophys 71: 291-297, 2015.

(i) (9) This work is licensed under a Creative Commons Attribution-NonCommercial-NoDerivatives 4.0 International (CC BY-NC-ND 4.0) License. 